\title{
Improved Algorithm for MODIS Satellite Retrievals of Aerosol Optical Depths Over Western North America
}

\section{Citation}

Drury, Easan E., Daniel J. Jacob, Jun Wang, Robert J.D. Spurr, and Kelly Chance. 2008. Improved algorithm for MODIS satellite retrievals of aerosol optical depths over western North America. Journal of Geophysical Research 113(D16204): 1-11.

\section{Published Version}

doi:10.1029/2007JD009573

\section{Permanent link}

http://nrs.harvard.edu/urn-3:HUL.InstRepos:3579188

\section{Terms of Use}

This article was downloaded from Harvard University's DASH repository, and is made available under the terms and conditions applicable to Other Posted Material, as set forth at http:// nrs.harvard.edu/urn-3:HUL.InstRepos:dash.current.terms-of-use\#LAA

\section{Share Your Story}

The Harvard community has made this article openly available.

Please share how this access benefits you. Submit a story.

\section{Accessibility}




\title{
Improved algorithm for MODIS satellite retrievals of aerosol optical depths over western North America
}

\author{
Easan Drury, ${ }^{1}$ Daniel J. Jacob, ${ }^{1}$ Jun Wang, ${ }^{2}$ Robert J. D. Spurr, ${ }^{3}$ and Kelly Chance ${ }^{4}$ \\ Received 5 November 2007; revised 28 March 2008; accepted 29 April 2008; published 21 August 2008.
}

[1] Quantitative evaluation of chemical transport models (CTMs) with aerosol optical depth (AOD) products retrieved from satellite backscattered reflectances can be compromised by inconsistent assumptions of aerosol optical properties and errors in surface reflectance estimates. We present an improved AOD retrieval algorithm for the MODIS satellite instrument using locally derived surface reflectances and CTM aerosol optical properties for the $0.47,0.65$, and $2.13 \mu \mathrm{m}$ MODIS channels. Assuming negligible atmospheric reflectance at $2.13 \mu \mathrm{m}$ in cloud-free conditions, we derive $0.65 / 2.13$ surface reflectance ratios at $1^{\circ} \times 1.25^{\circ}$ horizontal resolution for the continental United States in summer 2004 from the subset of top-of-atmosphere (TOA) reflectance data with minimal aerosol reflectance. We obtain a mean ratio of $0.57 \pm 0.10$ for the continental United States, with high values over arid regions and low values over the Midwest prairies. The higher surface reflectance ratios explain the high AOD bias over arid regions found in previous MODIS retrievals. We calculate TOA reflectances for each MODIS scene using local aerosol optical properties from the GEOS-Chem CTM, and fit these reflectances to the observed MODIS TOA reflectances for a best estimate of AODs for that scene. Comparison with coincident ground-based (AERONET) AOD observations at 16 sites in the western and central United States in summer 2004 shows poor correlation in the daily data but the correlation improves as averaging time increases. Averaging over the available coincident observations ( $n=11-44$ days) results in strong correlations $\left(\mathrm{R}_{0.47 \mu \mathrm{m}}=0.90, \mathrm{R}_{0.65 \mu \mathrm{m}}=0.67\right)$ and a $19 \%$ low bias, representing considerable improvement over the operational MODIS AOD products in this region.

Citation: Drury, E., D. J. Jacob, J. Wang, R. J. D. Spurr, and K. Chance (2008), Improved algorithm for MODIS satellite retrievals of aerosol optical depths over western North America, J. Geophys. Res., 113, D16204, doi:10.1029/2007JD009573.

\section{Introduction}

[2] Atmospheric aerosols are of major concern for public health and climate change, but their sources and atmospheric distributions remain poorly constrained. Observations to test global aerosol simulations from chemical transport models (CTMs) have been mainly confined to surface sites. Satellite-borne radiometers offer a new perspective for CTM evaluation and aerosol data assimilation by providing global aerosol optical depth (AOD) retrievals [Chin et al., 2004]. In this regard, the Moderate Resolution Imaging Spectroradiometer (MODIS) instruments aboard the NASA Terra and Aqua satellites are a particularly valuable resource. These instruments have 7 dedicated wavelength bands for aerosol retrieval $(0.47 \mu \mathrm{m}, 0.55 \mu \mathrm{m}, 0.65 \mu \mathrm{m}, 0.85 \mu \mathrm{m}$,

\footnotetext{
${ }^{1}$ School of Engineering and Applied Sciences, Harvard University, Cambridge, Massachusetts, USA.

${ }^{2}$ Department of Geosciences, University of Nebraska, Lincoln, Nebraska, USA

${ }^{3}$ RT Solutions, Inc., Cambridge, Massachusetts, USA.

${ }^{4}$ Atomic and Molecular Physics Division, Harvard-Smithsonian Center for Astrophysics, Cambridge, Massachusetts, USA.
}

Copyright 2008 by the American Geophysical Union. 0148-0227/08/2007JD009573\$09.00
$1.24 \mu \mathrm{m}, 1.65 \mu \mathrm{m}$, and $2.13 \mu \mathrm{m}$ ), a nadir resolution of $250-$ $500 \mathrm{~m}$, and a cross-track nadir swath of $2330 \mathrm{~km}$ providing global coverage every one to two days [Kaufman et al., 1997]. Daily AOD products have been retrieved operationally from the measured top-of-atmosphere (TOA) reflectances at $10 \times 10 \mathrm{~km}^{2}$ resolution since February 2000 (Terra) and June 2002 (Aqua) [Remer et al., 2005, 2006].

[3] MODIS AODs are most reliable over the oceans [Remer et al., 2002; Levy et al., 2005]. The collection 4 MODIS land AODs were subject to higher uncertainty and a persistent high bias [Ichoku et al., 2002; Kinne et al., 2003; Chin et al., 2004; Matsui et al., 2004; Abdou et al., 2005; Levy et al., 2005]. A preliminary evaluation of the most recent collection 5 MODIS land AODs shows significant global mean improvement [Levy et al., 2007b], but will require more studies to quantify regional improvements.

[4] The quality of land AOD products derived from MODIS depends critically on the ability to distinguish the atmospheric from the surface reflectance. This task is more difficult over land than over the ocean, where albedos are low and predictable (excepting glitter reflection cases) [Kaufman et al., 1997]. In the operational MODIS AOD retrieval over land, Level 2 TOA reflectances are estimated for every $10 \times 10 \mathrm{~km}^{2}$ scene from the ensemble of Level 1 
TOA reflectances at $0.5 \times 0.5 \mathrm{~km}^{2}$ within that scene that are cloud-free and have low $2.13 \mu \mathrm{m}$ surface reflectance, hence designated as "dark targets" [Gao et al., 2002; Martins et al., 2002; Remer et al., 2005, 2006; Levy et al., 2007b]. Level 2 TOA reflectances are averaged from this ensemble of cloud screened, "dark target" pixels at $0.47,0.65$ and $2.13 \mu \mathrm{m}$, and are further corrected for gaseous absorption by water vapor and ozone [Remer et al., 2006; Levy et al., 2007b]. At $2.13 \mu \mathrm{m}$ the atmospheric transmissivity is close to unity when aerosols are small or AODs are low, and the MODIS $2.13 \mu \mathrm{m}$ band measures surface reflectance in these conditions. Visible surface reflectances at 0.47 and $0.65 \mu \mathrm{m}$ are inferred from $2.13 \mu \mathrm{m}$ TOA reflectances through specified $0.47 / 0.65$ and $0.65 / 2.13$ surface reflectance relationships. The collection 4 MODIS AOD algorithm uses a fixed value of 0.50 ratio for these reflectance relationships [Kaufman et al., 1997, 2002; Remer et al., 2005]. The most recent collection 5 algorithm allows the $0.65 / 2.13$ surface reflectance ratio to vary over a range $0.39-0.67$ based on locally retrieved Normalized Difference Vegetation Index (NDVI) values and the sun/satellite measurement geometry [Remer et al., 2006; Levy et al., 2007b]. In collection 5, the $0.47 \mu \mathrm{m}$ surface reflectance is estimated by a $0.47 / 0.65$ ratio of 0.49 plus an intercept of $0.005 .\left(\rho_{0.47}^{s}=0.49^{*} \rho_{0.65}^{s}+\right.$ 0.005) [Remer et al., 2006; Levy et al., 2007b]. The atmospheric reflectances at 0.47 and $0.65 \mu \mathrm{m}$ are obtained by subtracting the surface reflectances from the measured TOA reflectances.

[5] Retrieving AODs from the residual atmospheric reflectances at 0.47 and $0.65 \mu \mathrm{m}$ requires independent estimation of the wavelength-dependent single scattering albedo $(\omega)$, which is the fraction of incident radiation that is scattered by an aerosol particle, and the scattering phase function $(P)$, which characterizes the directional intensity of scattered light. These aerosol optical properties depend on the aerosol chemical composition, size distribution, phase, and mixing state [Wang and Martin, 2007]. The operational MODIS AOD algorithm assigns fixed aerosol optical properties for individual continental regions and seasons (collection 4: [Kaufman et al., 1997; Remer et al., 2005] and collection 5: [Remer et al., 2006; Levy et al., 2007a]). A problem then in comparing the MODIS AODs to those generated by a CTM is that the CTM aerosol optical properties vary with the aerosol chemical composition in each model grid and time step and hence differ from those used in the MODIS retrieval. The comparison cannot be interpreted quantitatively in terms of an AOD discrepancy [Weaver et al., 2007].

[6] This paper presents a new method for inferring AODs over land from MODIS reflectances. We use (1) locally derived 0.65/2.13 surface reflectance ratios from subsets of MODIS data with minimal aerosol reflectance, (2) local aerosol optical properties from a global CTM (GEOS-Chem), and (3) an external multiple scattering radiative transfer model to simulate TOA reflectances which we use to infer AODs. We demonstrate that this new approach improves the retrieval of AODs from MODIS over the western and central United States, a region that has been identified as particularly problematic for the operational algorithms [Chu et al., 2002; Abdou et al., 2005]. Our method also allows quantitative evaluation of a CTM aerosol simulation through comparison of MODIS vs. CTM-derived TOA reflectances. Our study focuses on the continental United States during the July 1August 15, 2004 period of the ICARTT aircraft campaign [Fehsenfeld et al., 2006; Singh et al., 2006], because our longer-term interest is to use the ensemble of MODIS and ICARTT observations to analyze aerosol distributions over the United States. That analysis will be the topic of a subsequent paper.

\section{Data Sets}

\subsection{MODIS}

[7] We use MODIS Level 2 raster data (Collection 004, version 4.2.2. http://ladsweb.nascom.nasa.gov/data/ search.html) at $10 \times 10 \mathrm{~km}^{2}$ resolution from the Terra (1030 local time overpass) and Aqua (1330 local time overpass) satellites over the continental United States $\left(45-135^{\circ} \mathrm{W}, 25-55^{\circ} \mathrm{N}\right)$ for the period July 1 -August 15 , 2004. The data consist of cloud screened [Gao et al., 2002; Martins et al., 2002] TOA reflectances $\left(\rho_{\lambda}^{*}\right)$ at wavelengths $\lambda=0.47,0.65$, and $2.13 \mu \mathrm{m}$ over land, calculated from the measured backscattered radiances $I_{\lambda}$ :

$$
\rho_{\lambda}^{*}=\frac{I_{\lambda} \pi}{F_{\lambda} \mu_{o}}
$$

where $F_{\lambda}$ is the TOA solar radiation flux and $\mu_{o}$ is the cosine of the solar zenith angle. The Level 2 MODIS reflectances are corrected for ozone and water vapor absorption using climatological ozone profiles and water vapor from the National Centers for Environmental Prediction (NCEP), and suitable absorption cross sections taken from the literature [Vermote et al., 1997; Remer et al., 2006]. We did not find significant differences between the reflectances measured by Terra and Aqua during our study period.

[8] We associate each $10 \times 10 \mathrm{~km}^{2}$ MODIS reflectance scene with $1^{\circ} \times 1.25^{\circ}$ grid squares for the continental United States, corresponding to the native resolution of the GEOS-Chem CTM. This yields 200-1000 measurements per grid square for the summer of 2004. We remove data where we expect sub-grid surface water contamination, diagnosed by $2.13 \mu \mathrm{m}$ reflectance values less than 0.03 [Levy et al., 2005].

[9] We also obtained collection 4 MODIS AODs (level 2, filtered in the same manner as the reflectances above) [Kaufman et al., 1997; Remer et al., 2005] and collection 5 MODIS AODs (level 3, quality assured) [Remer et al., 2006; Levy et al., 2007b] to compare with the MODIS AODs generated by our algorithm. Following the notation in the MODIS Algorithm Theoretical Basis Document (ATBD), we henceforth refer to collection 4 data as C004 and collection 5 data as C005 [Remer et al., 2005, 2006].

\subsection{AERONET}

[10] The global AERONET network consists of groundbased sun photometers that measure AODs at $0.34,0.38$, $0.44,0.50,0.67,0.87$, and $1.02 \mu \mathrm{m}$ with an uncertainty of \pm 0.01 [Holben et al., 2001]. We used hourly level 2 AERONET AOD data (cloud screened and quality assured [Smirnov et al., 2000]) from 31 stations in the United States and Canada. We selected AERONET AODs measured within \pm 1 hour of Terra and Aqua overpasses and compared 


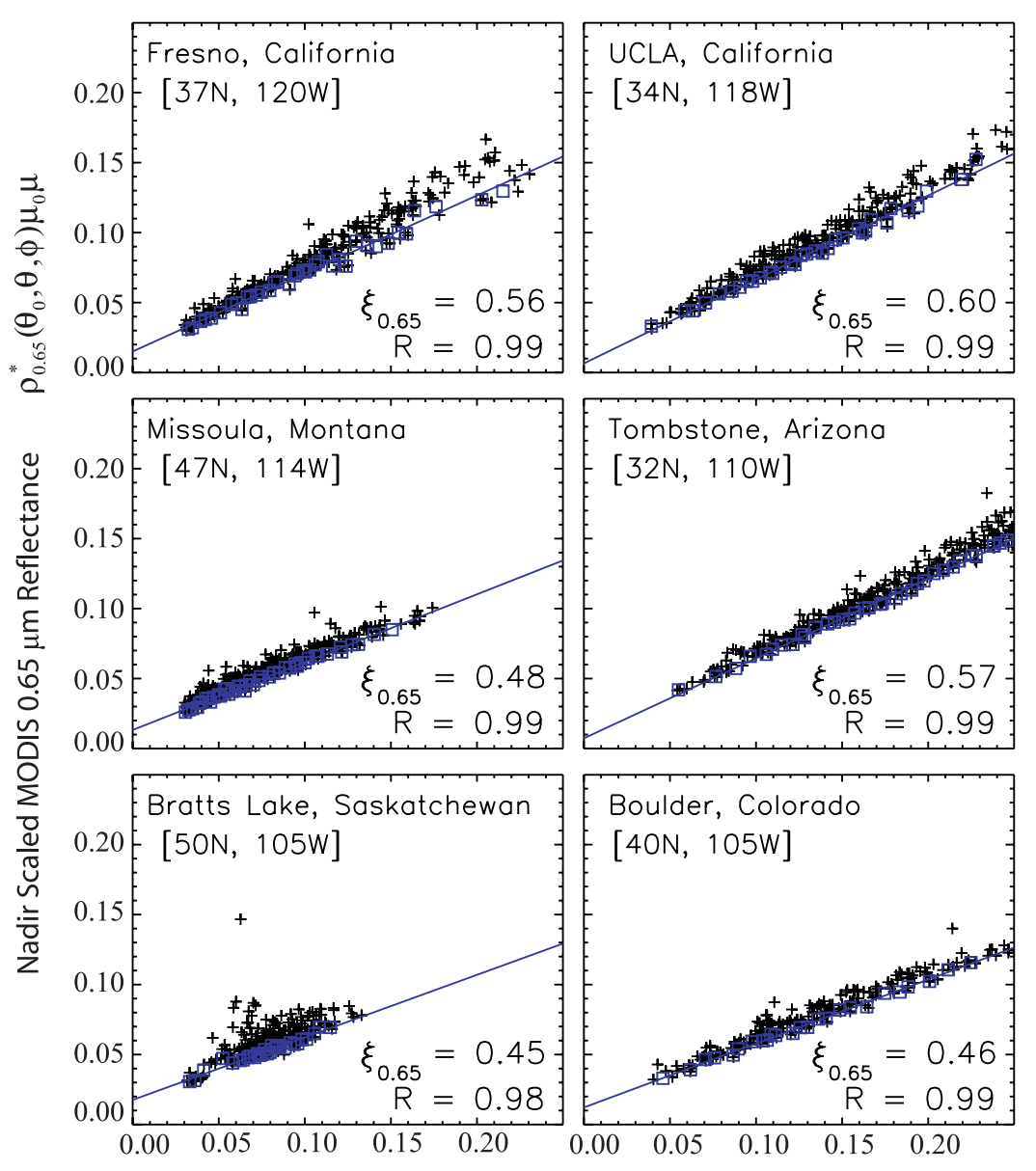

Nadir Scaled Atmospherically Corrected MODIS $2.13 \mu \mathrm{m}$ Reflectance

$$
F_{0.65}\left(\theta_{o}\right) T_{0.65}(\theta) \rho_{2.13}^{*}\left(\theta_{o}, \theta, \phi\right) \mu_{o} \mu
$$

Figure 1. Scatterplot of nadir scaled MODIS TOA reflectances at $0.65 \mu \mathrm{m} \rho_{0.65}^{*}\left(\theta_{o}, \theta, \phi\right) \mu_{o} \mu$ vs. $2.13 \mu \mathrm{m} F_{0.65}\left(\theta_{o}\right) T_{0.65}(\theta) \rho_{2.13}^{*}\left(\theta_{o}, \theta, \phi\right) \mu_{o} \mu$ for six illustrative $1^{\circ} \times 1.25^{\circ}$ grid squares in the United States and Canada with AERONET sites and for the July 1-August 15, 2004 period. The blue squares identify the subset of reflectance data used to define the linear lower envelope (see text) and from there the surface reflectance ratio $\xi_{0.65}$ by reduced-major-axis (RMA) linear regression. Correlation coefficients $(R)$ and RMA regression slopes $\left(\xi_{0.65}\right)$ are shown inset.

them with the collocated MODIS AODs retrieved within the $1^{\circ} \times 1.25^{\circ}$ grid square associated with each station. While we required only one collocated MODIS and AERONET AOD, we frequently retrieved multiple MODIS AODs within each grid square. We interpolated the $0.44 \mu \mathrm{m}$ and $0.50 \mu \mathrm{m}$ AERONET AODs to $0.47 \mu \mathrm{m}$ using the Angstrom exponent [Eck et al., 1999] and compared them with $0.47 \mu \mathrm{m}$ MODIS AODs. We compared the $0.67 \mu \mathrm{m}$ AERONET AODs with $0.65 \mu \mathrm{m}$ MODIS AODs.

\section{Derivation of Visible Surface Reflectances}

[11] Following the notation of the MODIS ATBD [Remer et al., 2005], the TOA reflectance $\rho_{\lambda}^{*}$ observed by MODIS can be expressed as the sum of the atmospheric reflectance $\rho_{\lambda}^{a}$ and the surface reflectance $\rho_{\lambda}^{s}$ :

$$
\rho_{\lambda}^{*}\left(\theta_{0}, \theta, \phi\right)=\rho_{\lambda}^{a}\left(\theta_{0}, \theta, \phi\right)+\frac{F_{\lambda}\left(\theta_{0}\right) T_{\lambda}(\theta)}{1-s_{\lambda} \rho_{\lambda}^{s}\left(\theta_{0}, \theta, \phi\right)} \rho_{\lambda}^{s}\left(\theta_{0}, \theta, \phi\right)
$$

where $\theta_{o}$ is the solar zenith angle, $\theta$ is the satellite zenith angle, $\phi$ is the relative azimuth angle between solar and satellite directions and $\rho_{\lambda}^{s}\left(\theta_{0}, \theta, \phi\right)$ is the bidirectional reflectance distribution function (BRDF) of the surface. The surface BRDF is corrected for the atmospheric attenuation of downward solar and upward line-of-sight beams in equation (2). Here $F_{\lambda}\left(\theta_{0}\right)$ is the downward transmission function representing solar attenuation from TOA to the surface, $T_{\lambda}(\theta)$ is the upward atmospheric transmission function, $s_{\lambda}$ is the atmospheric reflectance for upward radiation, and the $1 /\left(1-s_{\lambda} \rho_{\lambda}\right)$ term represents the summation over the infinite series of atmosphere-surface reflections.

[12] The atmosphere is approximately transparent at $2.13 \mu \mathrm{m}$ except under cloudy or unusually dusty conditions, so that the clear sky TOA reflectance at that wavelength can be assumed equal to the surface reflectance, $\rho_{2.13}^{*}=\rho_{2.13}^{s}$ [Kaufman et al., 2002]. Further assuming that the angular dependence of the BRDF does not vary with wavelength [Kaufman et al., 2002], one can 

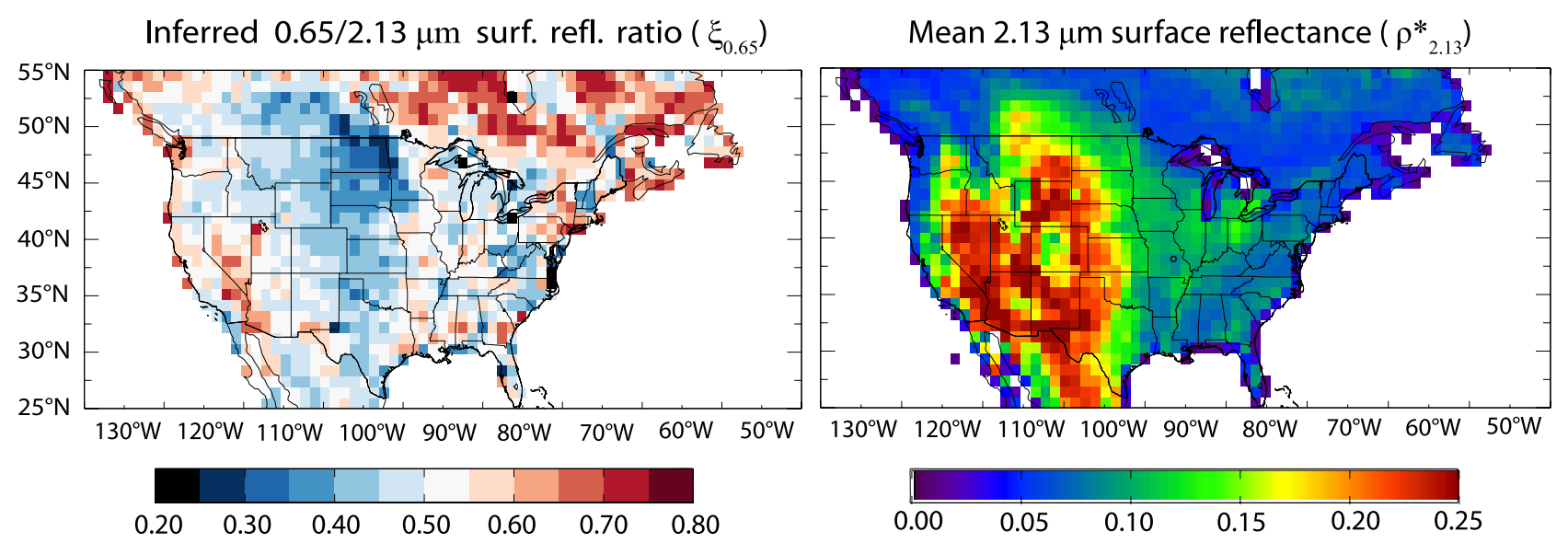

Figure 2. (left) Inferred $0.65 \mu \mathrm{m}$ to $2.13 \mu \mathrm{m}$ surface reflectance ratios $\xi_{0.65}=\rho_{0.65}^{s} / \rho_{2.13}^{*}$ and (right) mean $2.13 \mu \mathrm{m}$ top-of-atmosphere (TOA) reflectances $\rho_{2.13}^{*}$ over the July 1-August 15, 2004 period.

derive the surface reflectances at visible wavelengths by scaling to the $2.13 \mu \mathrm{m}$ reflectance:

$$
\rho_{\lambda}^{s}\left(\theta_{0}, \theta, \phi\right)=\xi_{\lambda} \rho_{2.13}^{*}\left(\theta_{0}, \theta, \phi\right)
$$

where the surface reflectance ratio $\xi_{\lambda}$ is independently specified. We described in the Introduction how $\xi_{0.47}$ and $\xi_{0.65}$ are specified in the C004 and C005 MODIS operational retrievals. Since the atmospheric reflectance contribution is greater at $0.47 \mu \mathrm{m}$ than $0.65 \mu \mathrm{m}$, deriving an estimate of $\xi_{0.47}$ is more difficult than for $\xi_{0.65}$, as will be explained below. The C004 MODIS operational algorithm assumed $\xi_{0.47}=\xi_{0.65} / 2$ [Levy et al., 2007b] and we do the same here. The $\mathrm{C} 005$ algorithm makes a similar assumption, as given in the Introduction.

[13] We present here a new approach to estimate the surface reflectance ratio $\xi_{0.65}$ for a given location from the relationship between the MODIS TOA reflectances at 0.65 and $2.13 \mu \mathrm{m}$. We use for this purpose the subset of local MODIS TOA reflectances with the lowest aerosol reflectance values, diagnosed as described below. Under such conditions, the atmosphere is optically thin so that the atmospheric reflectance varies linearly with AOD, and we can further assume $s_{\lambda} \ll 1$. Equation (2) becomes

$$
\begin{aligned}
\rho_{0.65}^{*}\left(\theta_{o}, \theta, \phi\right)= & \frac{\tau_{0.65} \omega_{0.65} P_{0.65}\left(\theta_{o}, \theta, \phi\right)}{\mu_{o}, \mu} \\
& +F_{0.65}\left(\theta_{o}\right) T_{0.65}(\theta) \xi_{0.65} \rho_{2.13}^{*}\left(\theta_{o}, \theta, \phi\right)
\end{aligned}
$$

where $\tau_{0.65}$ is the atmospheric optical depth at $0.65 \mu \mathrm{m}$, and $\omega$ and $P$ are respectively the single-scattering albedo and scattering phase function for the complete atmosphere (not just aerosol). Further multiplying by $\mu_{o} \mu$ removes the dependence of TOA reflectance on atmospheric path length, giving nadir scaled reflectances $\rho_{\lambda}^{*} \mu_{o} \mu$ :

$$
\begin{aligned}
\rho_{0.65}^{*}\left(\theta_{o}, \theta, \phi\right) \mu_{o} \mu= & \tau_{0.65} \omega_{0.65} P_{0.65}\left(\theta_{o}, \theta, \phi\right) \\
& +\xi_{0.65} \cdot F_{0.65}\left(\theta_{o}\right) T_{0.65}(\theta) \rho_{2.13}^{*}\left(\theta_{o}, \theta, \phi\right) \mu_{o} \mu
\end{aligned}
$$

[14] We see from equation (5) that a scatterplot of $\rho_{0.65}^{*}$ $\left(\theta_{o}, \theta, \phi\right) \mu_{o} \mu$ vs. $F_{0.65}\left(\theta_{o}\right) T_{0.65}(\theta) \rho_{2.13}^{*}\left(\theta_{o}, \theta, \phi\right) \mu_{o} \mu$ in an ensemble of MODIS observations of the same scene at different times and from different angles should have as lower envelope a line of slope $\xi_{0.65}$, with enhancements of $\rho_{0.65}^{*}\left(\theta_{o}, \theta, \phi\right) \mu_{o} \mu$ above that line representing the effect of atmospheric scattering. For the purpose of defining this lower envelope we approximate the transmission function product $F_{0.65}\left(\theta_{o}\right) T_{0.65}(\theta)$ in equation (5) using Rayleigh optical depths. Sample scatterplots are shown in Figure 1 for six $1^{\circ} \times 1.25^{\circ}$ grid squares, each containing an AERONET station. The lower envelope is well defined by a regression line $(\mathrm{R}=0.99$ in all cases $)$, which demonstrates that a single scaling factor $\xi_{0.65}$ is appropriate for a given location and season under a range of viewing conditions. To quantify this lower envelope, we bin the $2.13 \mu \mathrm{m}$ nadir scaled reflectances $F_{0.65}\left(\theta_{o}\right) T_{0.65}(\theta) \rho_{2.13}^{*}\left(\theta_{o}, \theta, \phi\right) \mu_{o} \mu$ sequentially in groups of eight and take the lower two of each group (blue squares in Figure 1). We then obtain $\xi_{0.65}$ from this subset as the slope of the reduced major axis (RMA) linear regression.

[15] The values of $\xi_{0.65}$ derived from Figure 1 range from 0.45 to 0.60 . Figure 2 shows our map of derived $\xi_{0.65}$ values for North America during July 1-August 15, 2004, together with the mean $2.13 \mu \mathrm{m}$ MODIS TOA reflectances $\left(\rho_{2.13}^{*}\right)$ for that period. The spatial mean of the reflectance ratio is $\xi_{0.65}=0.57 \pm 0.10$ for the continental domain, as compared to $\xi_{0.65}=0.5$ assumed in the MODIS C004 operational product [Remer et al., 2005]. We find that $\xi_{0.65}$ is highest $(0.5-0.7)$ over the arid Southwest, parts of the eastern US, and the boreal forests in eastern Canada. It is lowest $(0.3-$ $0.5)$ over the Midwest prairies. The $2.13 \mu \mathrm{m}$ reflectances $\left(\rho_{2.13}^{*}\right)$ are highest in the arid Southwest, and lowest in forested regions in the eastern US and Canada. Bias in the $\xi_{0.65}$ estimate translates into a reverse bias in atmospheric reflectance estimates and retrieved AODs. We see that this bias is particularly important in arid areas where both the surface reflectance ratio $\xi_{0.65}$ and the $2.13 \mu \mathrm{m}$ reflectances $\rho_{2.13}^{*}$ are high. This explains the finding from a number of studies that MODIS AODs are biased high over arid regions [Ichoku et al., 2002; Kinne et al., 2003; Chin et al., 2004; Matsui et al., 2004; Abdou et al., 2005; Levy et al., 2005]. We tried to apply the same method to derive $0.47 / 2.13 \mu \mathrm{m}$ surface reflectance ratios $\xi_{0.47}$ from the observed nadir scaled reflectances, but were unsuccessful in defining a 

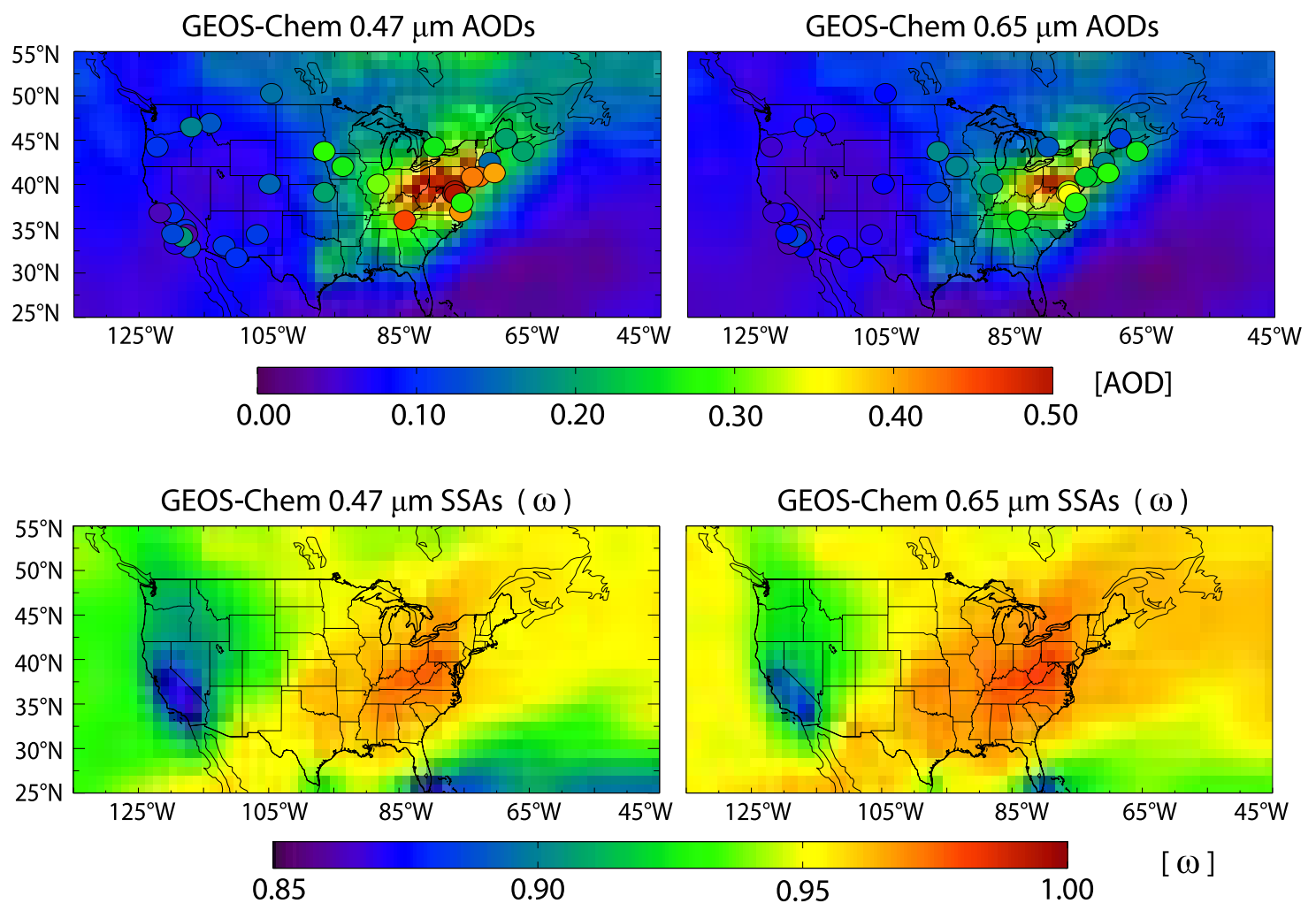

Figure 3. Mean GEOS-Chem CTM aerosol optical properties for July 1-August 15, 2004. AODs at $0.47 \mu \mathrm{m}$ and $0.65 \mu \mathrm{m}$ are plotted in the top row with mean observed AERONET AODs overlaid as filled circles. Single scattering albedos are plotted in the bottom row.

lower-envelope regression line. This can be explained by the stronger atmospheric scattering at 0.47 than at $0.65 \mu \mathrm{m}$, limiting the availability of data with sufficiently low atmospheric scattering to constrain the lower envelope. Therefore we assume $\xi_{0.47}=\xi_{0.65} / 2$, following the MODIS Collection 4 ATBD [Kaufman et al., 1997; Remer et al., 2005].

\section{CTM Simulation of MODIS Reflectances}

[16] As noted in the Introduction, a comparison of CTM AODs with MODIS AODs cannot be interpreted quantitatively in terms of AOD discrepancies if the aerosol optical properties assumed in the MODIS retrieval are inconsistent with those in the CTM simulation. We overcome this issue here by using local GEOS-Chem CTM aerosol information to simulate TOA reflectances for each $10 \times 10 \mathrm{~km}^{2}$ MODIS scene. GEOS-Chem TOA reflectances are calculated at the time and location of each MODIS scene (including both Terra and Aqua overpasses) in the local sun-satellite geometry of the MODIS instrument. In a subsequent paper we will apply the method to compare MODIS and GEOS-Chem TOA reflectances for evaluation of the GEOS-Chem aerosol simulation; here we apply it to derive an improved MODIS AOD product.

[17] GEOS-Chem is driven by GEOS-4 assimilated meteorological data from the NASA Global Modeling and Assimilation Office (GMAO). The GEOS-4 data have $1^{\circ} \times 1.25^{\circ}$ horizontal resolution with 48 vertical layers and 6-h temporal resolution (3-h for surface properties).
We degrade the horizontal resolution to $2^{\circ} \times 2.5^{\circ}$ for the GEOS-Chem simulation. GEOS-Chem simulates mass concentrations for six aerosol types: (1) dust in five size classes, (2) sulfate, (3) nitrate, (4) black carbon (BC), (5) organic carbon (OC), and (6) fine and coarse mode sea salt. Detailed descriptions of the GEOS-Chem aerosol simulation including evaluations with surface observations in the US are given by Fairlie et al. [2007] for dust, Alexander et al. [2005] for sea salt, and Park et al. [2003, 2004, 2006] for the other aerosol types. Specific evaluation with ICARTT aircraft aerosol observations over eastern North America during summer 2004 is presented by Heald et al. [2006]. Biomass burning sources for the summer 2004 are from a daily inventory constrained by satellite fire counts [Turquety et al., 2007].

[18] Aerosol optical properties in GEOS-Chem are derived from simulated aerosol mass concentrations by assuming that the aerosols have lognormal size distributions with typedependent size parameters, hygroscopic growth factors, and refractive indices taken from the Global Aerosol Data Set (GADS) [Koepke et al., 1997]. Hygroscopic growth is calculated using GEOS-4 relative humidity fields at the original $1^{\circ} \times 1.25^{\circ}$ resolution. A standard Mie code is used to calculate optical properties for each aerosol type. We assume an external mixture of aerosols and sum over aerosol types to generate an optical depth, an ensemble single scattering albedo, and an ensemble scattering phase function for each vertical model layer.

[19] The mean GEOS-Chem AODs and single scattering albedos for the MODIS overpass times (1030 and 1330 

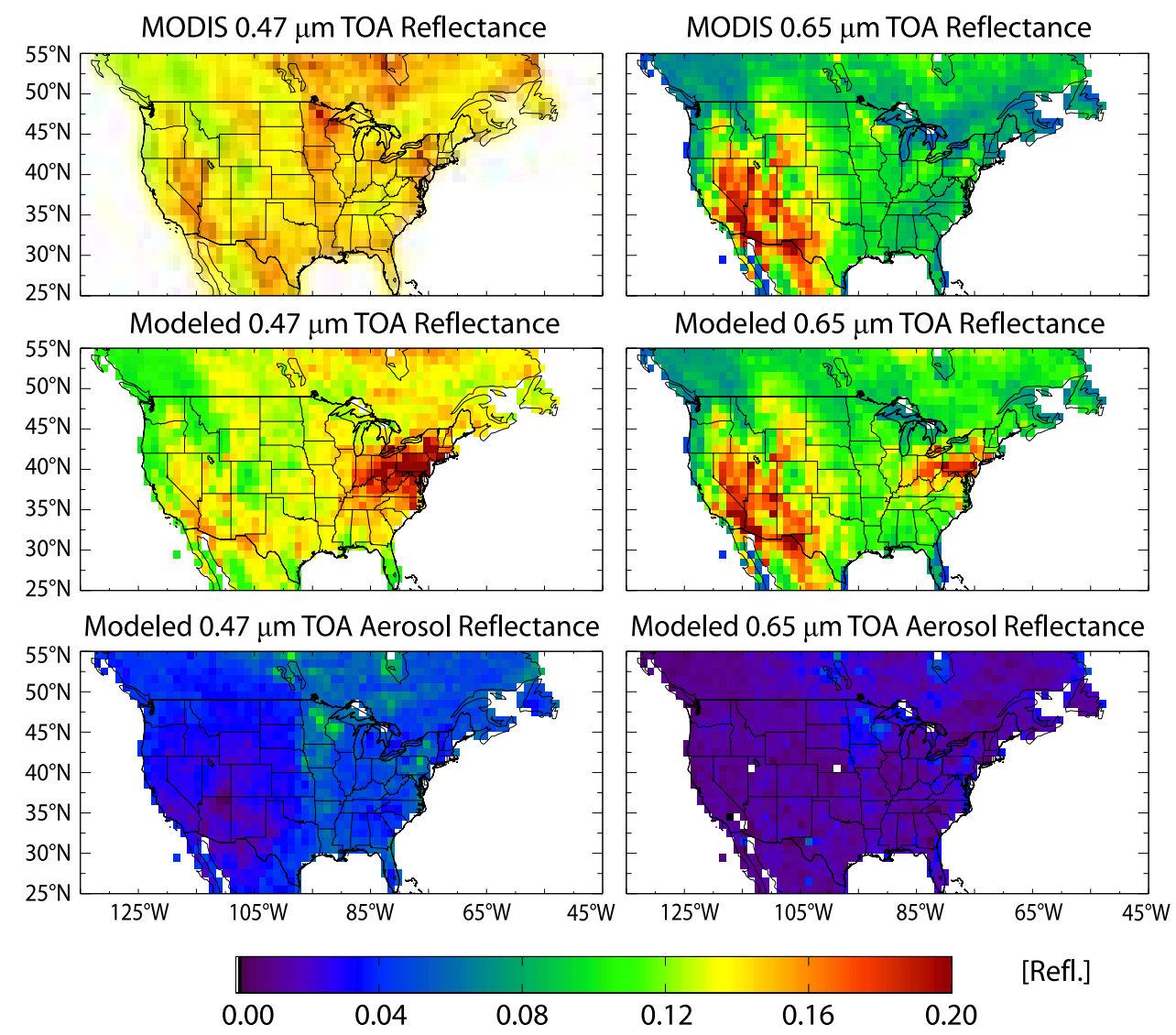

Figure 4. Mean top-of-atmosphere (TOA) reflectances for the July 1-August 15, 2004 period measured by MODIS (top row) and simulated by GEOS-Chem for the MODIS scenes (middle row). The bottom row shows the aerosol contribution to the TOA reflectance simulated by GEOS-Chem, as derived by difference with a radiative transfer calculation including no aerosol scattering.

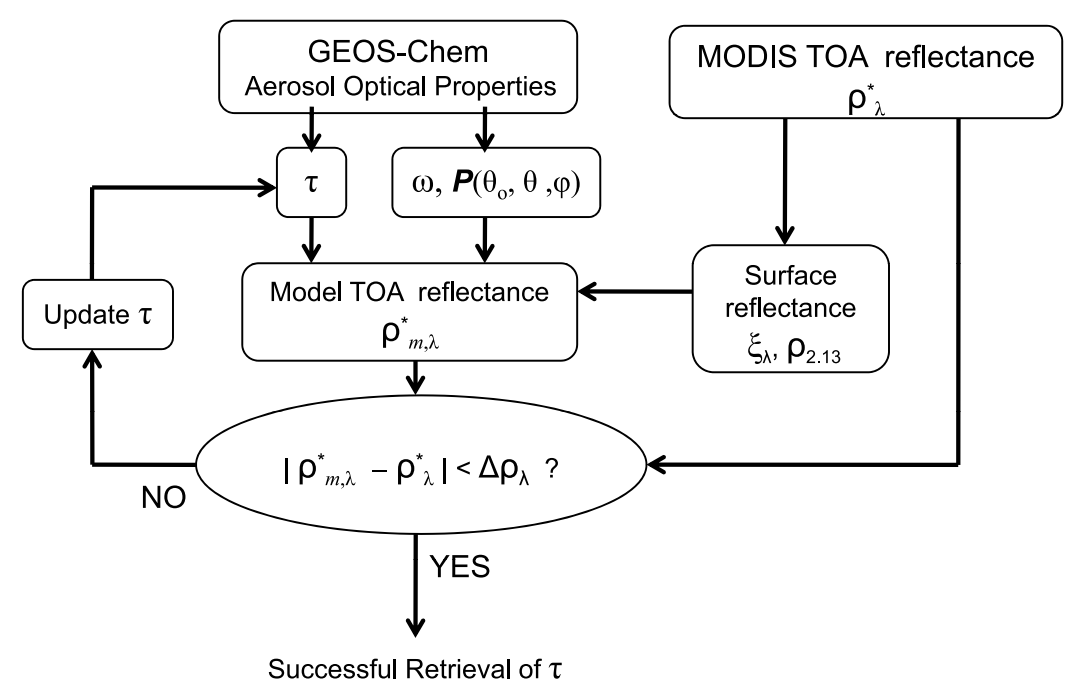

Figure 5. Flow chart of our AOD $(\tau)$ retrieval algorithm. Aerosol optical properties and initial AODs are from the GEOS-Chem CTM (section 4). These optical properties, along with the local estimate of surface reflectance from the MODIS data (section 3), are used to model TOA reflectance using the LIDORT radiative transfer model for the appropriate sun-satellite geometry of the MODIS instrument. The AODs are iteratively scaled until simulated reflectances match MODIS reflectances to within error tolerances $\Delta \rho_{\lambda}$ of 0.005 and 0.001 at $0.47 \mu \mathrm{m}$ and $0.65 \mu \mathrm{m}$, respectively. 
MODIS $0.47 \mu \mathrm{m}$ AODs (this work)
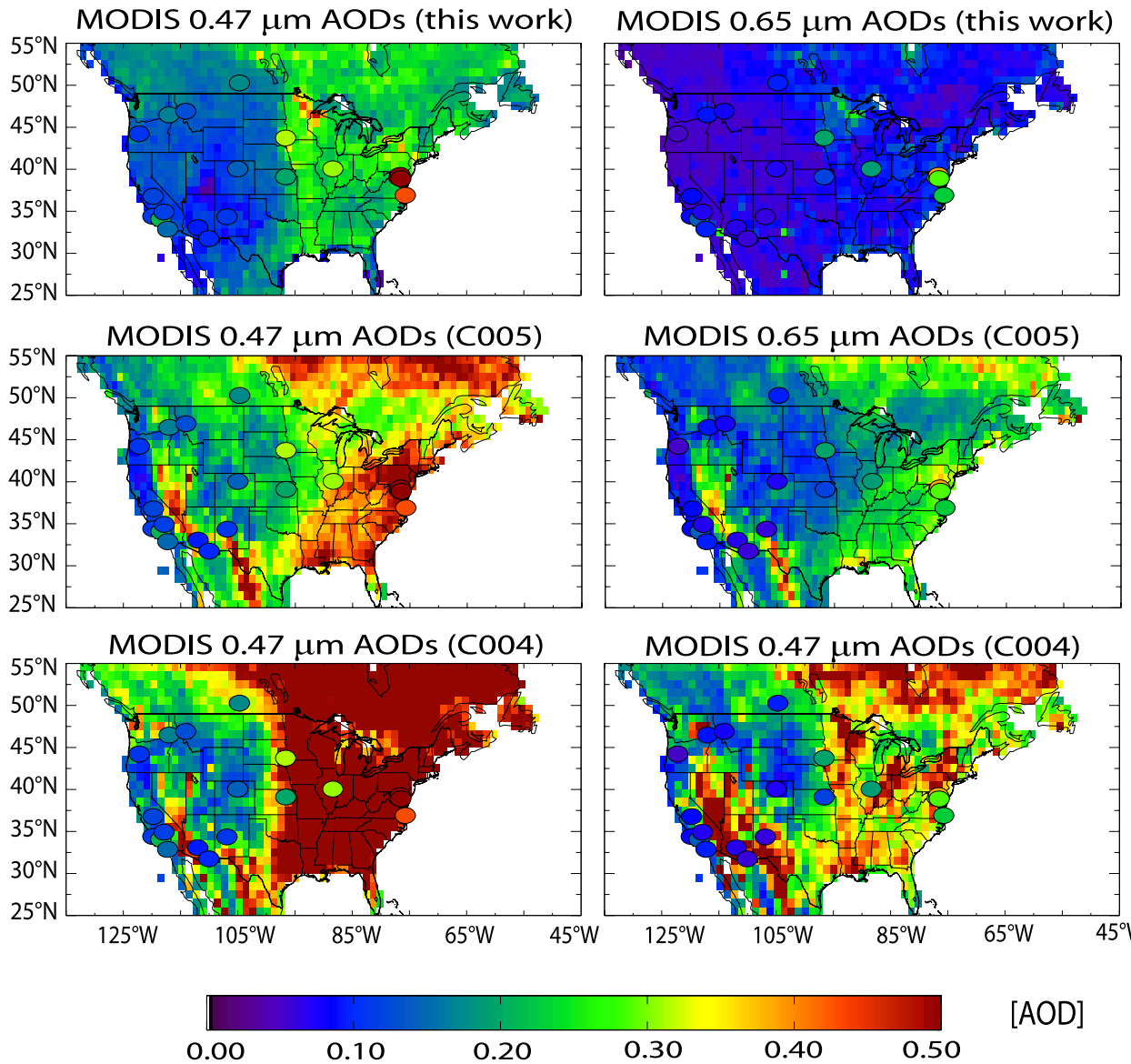

MODIS 0.47 $\mu \mathrm{m}$ AODs (C004)

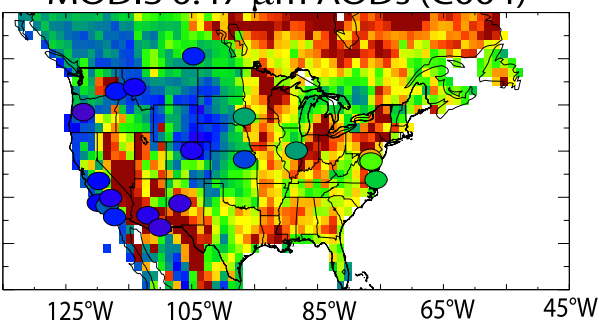

[AOD]

Figure 6. Mean AODs over North America at 0.47 and $0.65 \mu \mathrm{m}$ for the period July 1-August 15, 2004. MODIS retrievals from this work (first panels) are compared to the operational products C005 [Remer et al., 2006] and C004 [Remer et al., 2005]. Mean AERONET AODs for the same period are shown as circles.

local time) during July 1 -August 15, 2004 are plotted in Figure 3. Mean AERONET AODs collected within \pm 1 hour of MODIS overpasses are overlaid. GEOS-Chem AODs capture the general spatial distribution of AODs measured by AERONET, with correlations ( $\mathrm{R}$ values) of 0.67 and 0.59 at $0.47 \mu \mathrm{m}$ and $0.65 \mu \mathrm{m}$, respectively. The GEOSChem AODs are biased low at $0.47 \mu \mathrm{m}$ relative to AERONET with an RMA regression slope of $0.85 \pm 0.14$, and biased high at $0.65 \mu \mathrm{m}$ with a regression slope of $1.25 \pm$ 0.22 . The modeled AODs are highest over the industrial Midwest where the AOD is dominated by sulfate aerosols, resulting also in high single scattering albedos. Single scattering albedos are lowest over the Los Angeles Basin where the model has high concentrations of black carbon and dust. Low single-scattering albedos over Florida are due to Saharan dust.

[20] We use the LIDORT discrete ordinate multiple scattering radiative transfer model Version 2.3 [Spurr et al., 2001; Spurr, 2002] to simulate TOA reflectances for each $10 \times 10 \mathrm{~km}^{2}$ MODIS scene on the basis of the GEOS-Chem aerosol information. LIDORT provides exact treatment of the single-scattering radiation field and a pseudo-spherical capability to deal with solar beam attenuation in a curved atmosphere. We include molecular
(Rayleigh) scattering based on the scattering cross sections from Bodhaine et al. [1999] weighted by the relative spectral response functions of the MODIS instrument (ftp://ftp.mcst.ssai.biz/pub/permanent/MCST/PFM_L1B LUT_4-30-99/L1B_RSR_LUT/). We scale Rayleigh optical depths using local GEOS-4 surface pressures. Polarization is neglected in this version of LIDORT.

[21] Figure 4 compares the TOA reflectances measured by MODIS for the July 1 -August 15, 2004 period to the reflectances simulated by LIDORT based on GEOS-Chem inputs. The surface reflectances used for this simulation were described in section 3. Also shown in Figure 4 is the aerosol contribution to the TOA reflectance, obtained as the difference between LIDORT calculations with and without aerosol. This contribution is small, highlighting the importance of accurately estimating surface reflectance in the AOD retrieval. For example, TOA reflectances at $0.65 \mu \mathrm{m}$ are higher in the Southwest than in the Northeast because of high surface reflectances. GEOS-Chem shows maximum aerosol reflectances in the Northeast, consistent with the AERONET data (Figure 3), and producing TOA reflectance maxima in the middle rows of Figure 4. The MODIS TOA reflectance data show much less enhancement in the North- 
east (top rows); this discrepancy is discussed briefly below and will be the topic of a subsequent paper.

\section{Retrieving MODIS Aerosol Optical Depths}

[22] We retrieve here MODIS AODs from the comparison of modeled (LIDORT/GEOS-Chem) to observed (MODIS) TOA reflectances (Figure 4) by fitting the modeled AODs to match the observed reflectances. The inversion is not linear, since the atmosphere cannot in general be assumed optically thin. Therefore the fitting is performed iteratively until the difference between modeled and measured reflectance is within $\Delta \rho_{0.47}^{*}= \pm 0.005$ and $\Delta \rho_{0.65}^{*}= \pm 0.001$. These limits correspond to the uncertainty caused by neglecting polarization in the radiative transfer code [Levy et al., 2004]. This leads to precision limits of $\Delta \tau_{0.47}= \pm 0.05$ and $\Delta \tau_{0.65}=$ \pm 0.01 in AODs retrieved for each scene. No further quality assurance is applied in the retrieval.

[23] Figure 5 is a flow chart of our AOD retrieval algorithm, and Figure 6 shows the mean $0.47 \mu \mathrm{m}$ and $0.65 \mu \mathrm{m}$ AODs derived over the continental US for the July 1 -August 15, 2004 period. In Figure 6, our retrieval is compared to the C004 and C005 MODIS operational products. Mean AERONET AODs collected within \pm 1 hour of MODIS retrievals are plotted as filled circles for stations with at least 9 days of coincident measurements from the July 1-August 15 period. Our retrieved AODs are consistent with AERONET AODs over the western and central US but too low for the two east coast sites (SERC and GSFC in Maryland with 12 and 13 days of coincident measurements respectively). The SERC and GSFC AERONET instruments recorded high AODs $(>1.0)$ on a few days associated with high relative humidity, which we underestimate in our MODIS retrieval. These sites also show large diurnal variability, which is not seen at sites in the western and central US, and may require increasing the temporal window of AERONET data to match the $1^{\circ} \times 1.25^{\circ}$ spatial extent of MODIS AODs for an accurate comparison [Ichoku et al., 2002]. These issues are unique to the SERC and GSFC and require further investigation; for now, we exclude these two sites from further discussion and focus on sites in the western and central US where the comparison between MODIS and AERONET is more robust.

[24] Figure 7 compares the mean of coincident MODIS and AERONET AODs for the 16 AERONET stations in the western and central US during July 1-August 15, 2004. Values are given for each site in Table 1. Our retrieved AODs are strongly correlated with the AERONET observations at $0.47 \mu \mathrm{m}(\mathrm{R}=0.90)$, with a mean bias of $-19 \%$ as indicated by the RMA slope. At $0.65 \mu \mathrm{m}$ the correlation is weaker $(\mathrm{R}=0.67)$ but the bias is similar to that at $0.47 \mu \mathrm{m}$. We expect the retrieval at $0.65 \mu \mathrm{m}$ to be noisier than at $0.47 \mu \mathrm{m}$ because the surface reflectance is larger while the aerosol reflectance is weaker. At both wavelengths, we achieve considerable improvement over the operational MODIS products in this region, for which correlations with the AERONET data are poor and show large positive bias.

[25] The comparisons of MODIS vs. AERONET in Figure 7 are based on averaging over 11 to 44 days of data depending on the site (see Table 1), corresponding to the availability of coincident observations over July 1-
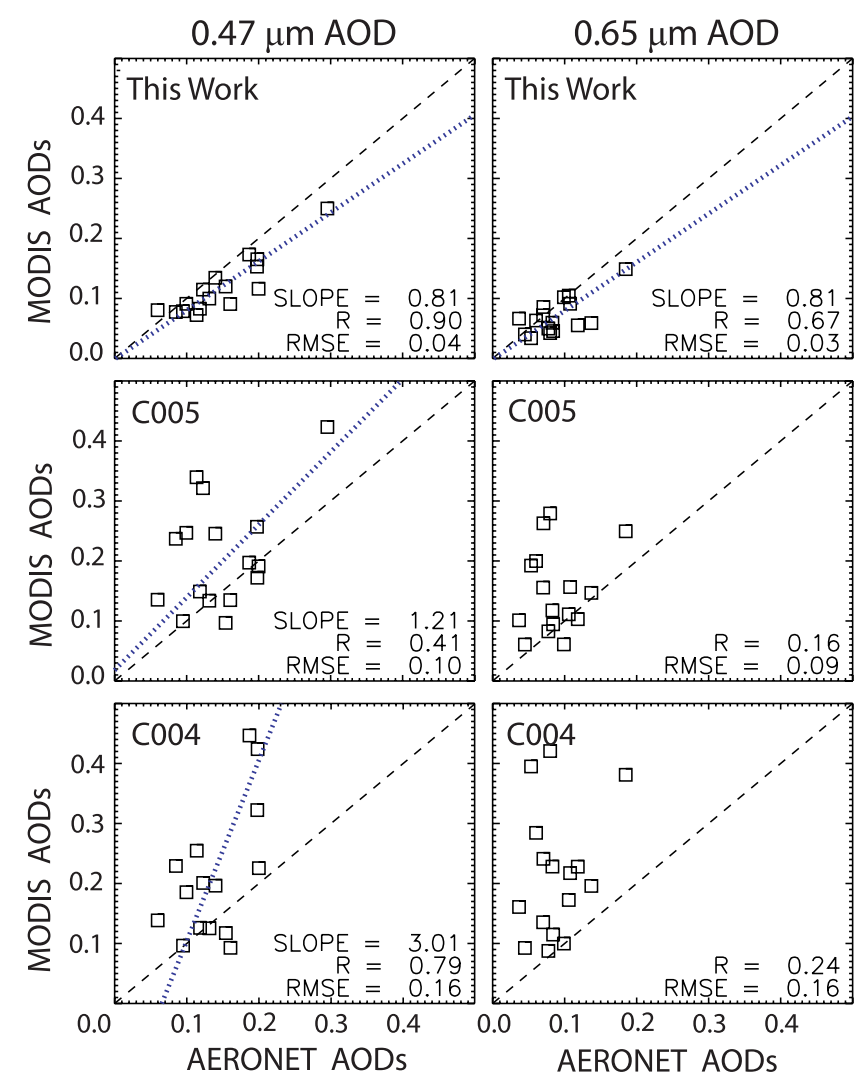

Figure 7. Scatterplots of MODIS vs. AERONET AODs for summer 2004 at the 16 AERONET stations listed in Table 1 . Values are means for the July 1 -August 15 period. MODIS retrievals from this work (first panels) are compared to the MODIS operational retrievals C005 (second panels) and $\mathrm{C} 004$ (third panels). Correlation coefficients (R) and root mean square errors (RMSE) are shown. We include the RMA regression lines (dotted) and corresponding slopes (inset) for our retrieved AODs, but not for the $\mathrm{C} 004$ and $\mathrm{C} 005$ AODs because their correlations are not significant at the $95 \%$ confidence limit. The $1: 1$ line is shown as dashed.

August 15, 2004. We examined the quality of the MODIS retrieval at shorter timescales by averaging the MODIS and AERONET AODs over time periods ranging from 1 to 9 days. We calculated the correlations and RMS errors for each averaging period, and the results are shown in Figure 8 . We find that our daily retrievals are not reliable $(\mathrm{R}=0.32, \mathrm{RMSE}=0.10$ at $0.47 \mu \mathrm{m})$ but weekly retrievals are much better $(\mathrm{R}=0.64, \mathrm{RMSE}=0.05)$ though still not as good as the retrievals averaged over the full 11-44 days $(\mathrm{R}=0.90, \mathrm{RMSE}=0.04)$. The operational C004 and C005 MODIS retrievals are less successful than our retrieval over all averaging times, with $\mathrm{R}$ values remaining below 0.6 and RMSEs remaining in excess of 0.10 . R decreases with averaging time for $\mathrm{C} 005$ which reflects the different patterns of bias in the western and central US (Figure 6) that are sampled differently for each averaging time. RMS errors decrease with averaging time for all MODIS retrievals. 


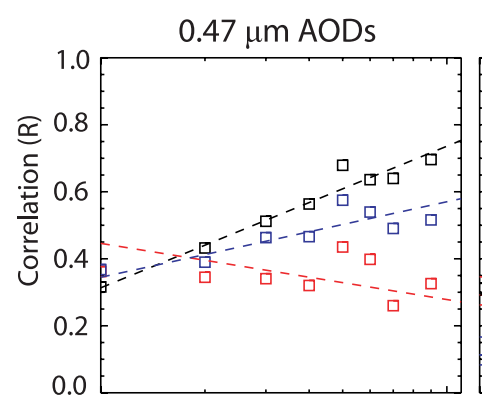

$0.65 \mu \mathrm{m}$ AODs
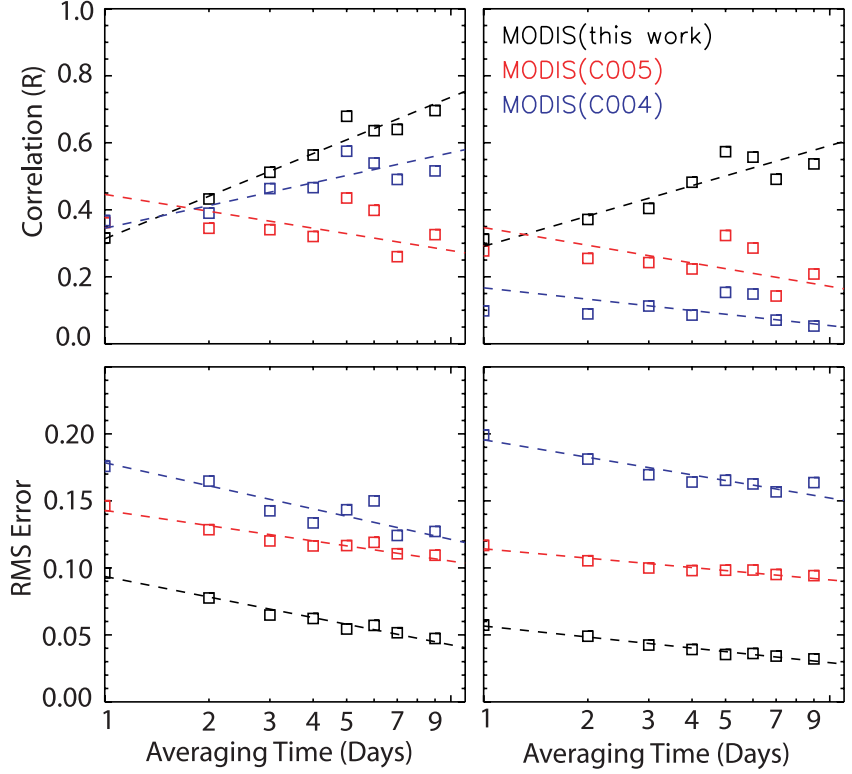

Figure 8. Comparison of MODIS and AERONET AODs for different averaging times from 1 to 9 days. Comparison statistics are shown for the ensemble of western and central US sites in Table 1 and for the July 1 -August 15, period: correlation coefficients (top) and root mean square errors (bottom). Results from our MODIS retrieval algorithm (black symbols) are compared to the operational C005 (red) and C004 (blue) MODIS retrievals. Dashed lines are regressions added to aid the eye.

[26] In an effort to understand the source of error in our daily MODIS AOD retrieval, we correlated the difference between the daily MODIS vs. AERONET AODs with different variables including the fraction of cloud cover, the $2.13 \mu \mathrm{m}$ reflectance intensity, the scattering geometry, the relative humidity, the number of $10 \times 10 \mathrm{~km}^{2}$ MODIS reflectance data entering into the $1^{\circ} \times 1.25^{\circ}$ average, and the number of "dark target" pixels in the Level 1 data used to calculate Level 2 reflectance statistics. We did not find a strong correlation with any of these variables.

\section{Conclusions}

[27] We have developed a new method for retrieving aerosol optical depths (AODs) over land from top-ofatmosphere (TOA) reflectances observed by the MODIS satellite instrument, and applied this method to continental North America during the summer of 2004 (July 1-August $15)$. In this method we first obtain local estimates of visiblechannel surface reflectances derived from a subset of the reflectance data where the aerosol contribution to TOA reflectance is small. These surface reflectances are used to isolate the atmospheric reflectance signal from the TOA reflectance measured by MODIS. We then use local aerosol optical properties from a chemical transport model (GEOSChem CTM) as input to a multiple scattering radiative transfer model (LIDORT) to generate TOA reflectances for each $10 \times 10 \mathrm{~km}^{2}$ MODIS scene. AODs are then retrieved by fitting the simulated reflectances to the MODIS 
TOA reflectances. Aside from any advantage gained from the use of local CTM aerosol optical properties rather than mean climatology to constrain the retrieval, this method ensures consistency between MODIS and CTM AODs (or TOA reflectances) for purposes of quantitative comparison.

[28] As in the MODIS operational product [Remer et al., 2006], we assume that the MODIS $2.13 \mu \mathrm{m}$ channel measures the surface reflectance (the atmosphere is transparent at that wavelength), and infer the surface reflectances at 0.47 and $0.65 \mu \mathrm{m}$ (MODIS visible channels) by simple scaling. We determine the local $0.65 / 2.13$ surface reflectance ratio $\left(\xi_{0.65}\right)$ in each $1^{\circ} \times 1.25^{\circ}$ grid square from the lower envelope of the relationship between $0.65 \mu \mathrm{m}$ and $2.13 \mu \mathrm{m}$ TOA reflectances observed by MODIS. This lower envelope is well approximated by a regression line $(\mathrm{R}=$ $0.99)$, supporting the use of a constant scaling factor $\xi_{0.65}$ for a given location. For continental North America in summer we find a mean ratio $\xi_{0.65}=0.57 \pm 0.10$, higher than the operational MODIS AOD algorithm values of $\xi_{0.65}=0.50(\mathrm{C} 004)$ and $\xi_{0.65}=0.39-0.67$ (C005). We find high $\xi_{0.65}$ values $(0.5-0.7)$ over the arid Southwest and over forested regions of the East, and low values $(0.3-0.5)$ over the Midwestern prairies. The high $\xi_{0.65}$ values over the Southwest coincide with particularly high surface reflectances, where an underestimate of $\xi_{0.65}$ leads to a large overestimate in retrieved AOD. We can thus explain why the operational MODIS C004 AODs used in a number of aerosol characterization studies have been found to be biased high over land and particularly in arid regions [Ichoku et al., 2002; Kinne et al., 2003; Chin et al., 2004; Matsui et al., 2004; Abdou et al., 2005; Levy et al., 2005].

[29] We used aerosol optical properties derived from the GEOS-Chem CTM in conjunction with the LIDORT radiative transfer model to generate simulated TOA reflectances for comparison with the MODIS data. We then retrieved AODs for each MODIS scene by iteratively scaling the GEOS-Chem AODs to fit the observed TOA reflectances. We compared this AOD retrieval to the operational MODIS AOD products (C004 and C005) and to coincident groundbased AOD observations from the AERONET network averaged over the July 1-August 15, 2004 period. We found a considerable improvement in our MODIS retrieval over the western and central US, with high correlation to the AERONET data $(\mathrm{R}=0.90$ at $0.47 \mu \mathrm{m})$ and a $19 \%$ low bias. In contrast, the operational MODIS products show poor correlation and a strong bias in comparison to the AERONET data for that region. The retrieval of AODs is much better at 0.47 than at $0.65 \mu \mathrm{m}$ because of the higher signal to noise ratio. The quality of the retrieval was much less in the eastern US and we will address that issue in a subsequent paper.

[30] We determined the quality of our MODIS retrieval over the western and central US for different averaging times through corresponding comparison with AERONET. Poor correlation $(\mathrm{R}=0.32$ at $0.47 \mu \mathrm{m})$ is found in the daily data. This improves with weekly averaging to $(\mathrm{R}=0.64)$. Our retrieval is more successful than the C004 and C005 operational retrievals for all averaging times in this region. Interpretation of daily MODIS AOD data over western North America should be subject to much caution.
[31] Acknowledgments. This work was funded by the NASA Atmospheric Composition Modeling and Analysis Program. Easan Drury was supported by a NASA Earth and Space Science Graduate Fellowship. This work benefited greatly from conversations with Lorraine Remer, Rob Levy, Clark Weaver, Allen Chu, and Mian Chin at the NASA Goddard Space Flight Center (GSFC).

\section{References}

Abdou, W. A., D. J. Diner, J. V. Martonchik, C. J. Bruegge, R. A. Kahn, B. J. Gaitley, K. A. Crean, L. A. Remer, and B. Holben (2005), Comparison of coincident Multiangle Imaging Spectroradiometer and Moderate Resolution Imaging Spectroradiometer aerosol optical depths over land and ocean scenes containing Aerosol Robotic Network sites, J. Geophys. Res., 110, D10S07, doi:10.1029/2004JD004693.

Alexander, B., J. Savarino, C. C. W. Lee, R. J. Park, D. J. Jacob, M. H. Thiemens, Q. B. Li, and R. M. Yantosca (2005), Sulfate formation in seasalt aerosols: Constraints from oxygen isotopes, J. Geophys. Res., 110, D10307, doi:10.1029/2004JD005659.

Bodhaine, B. A., N. B. Wood, E. Dutton, and G. J. R. Slusser (1999), On Rayleigh optical depth calculations, J. Atmos. Ocean. Technol., 16, 1854-1861.

Chin, M., A. Chu, R. Levy, L. Remer, Y. Kaufman, B. Holben, T. Eck, P. Ginoux, and Q. Gao (2004), Aerosol distribution in the Northern Hemisphere during ACE-Asia: Results from global model, satellite observations, and sun photometer measurements, J. Geophys. Res., 109, D23S90, doi:10.1029/2004JD004829.

Chu, D. A., Y. J. Kaufman, C. Ichoku, L. A. Remer, D. Tanre, and B. N. Holben (2002), Validation of MODIS aerosol optical depth retrieval over land, Geophys. Res. Lett., 29(12), 8007, doi:10.1029/2002GL013205.

Eck, T. F., B. N. Holben, J. S. Reid, O. Dubovik, A. Smirnov, N. T. O'Neill I. Slutsker, and S. Kinne (1999), Wavelength dependence of the optical depth of biomass burning, urban, and desert dust aerosols, J. Geophys. Res., 104(D24), 31,333-31,349.

Fairlie, T. D., D. J. Jacob, and R. J. Park (2007), The impact of transpacific transport of mineral dust in the United States, Atmos. Environ., 41, $1251-1266$

Fehsenfeld, F. C., et al. (2006), International Consortium for Atmospheric Research on Transport and Transformation (ICARTT): North America to Europe-Overview of the 2004 summer field study, J. Geophys. Res., 111, D23S01, doi:10.1029/2006JD007829.

Gao, B.-C., Y. J. Kaufman, D. Tanre, and R.-R. Li (2002), Distinguishing tropospheric aerosols from thin cirrus clouds for improved aerosol retrievals using the ratio of $1.38 \mu \mathrm{m}$ and $1.24 \mu \mathrm{m}$ channels, Geophys. Res. Lett., 29(18), 1890, doi:10.1029/2002GL015475.

Heald, C. L., et al. (2006), Concentrations and sources of organic carbon aerosol in the free troposphere over North America, J. Geophys. Res., 111, D23S47, doi:10.1029/2006JD007705.

Holben, B. N., D. Tanre, and A. Smirnov (2001), An emerging groundbased aerosol climatology: Aerosol optical depth from AERONET, J. Geophys. Res., 106, 12,067-12,097.

Ichoku, C., D. A. Chu, S. Mattoo, Y. J. Kaufman, L. A. Remer, D. Tanre, I. Slutsker, and B. N. Holben (2002), A spatio-temporal approach for global validation and analysis of MODIS aerosol products, Geophys. Res. Lett., 29(12), 8006, doi:10.1029/2001GL013206.

Kaufman, Y. J., D. Tanré, H. R. L. A. Remer, E. Vermote, A. Chu, and B. N. Holben (1997), Operational remote sensing of tropospheric aerosol over land from EOS moderate resolution imaging spectroradiometer, J. Geophys. Res., 102(D14), 17,051-17,067.

Kaufman, Y. J., N. Gobron, B. Pinty, J. L. Widlowski, and M. M. Verstraete (2002), Relationship between surface reflectance in the visible and midIR used in MODIS aerosol algorithm-Theory, Geophys. Res. Lett., 29(23), 2116, doi:10.1029/2001GL014492.

Kinne, S., et al. (2003), Monthly averages of aerosol properties: A global comparison among models, satellite data, and AERONET ground data, J. Geophys. Res., 108(D20), 4634, doi:10.1029/2001JD001253.

Koepke, P., M. Hess, I. Schult, and E. P. Shettle (1997), Global Aerosol Data Set, Rep. No. 243, Max-Planck-Institut fur Meteorol., Hamburg, Germany.

Levy, R. C., L. Remer, and A. Y. J. Kaufman (2004), Effects of neglecting polarization on the MODIS aerosol retrieval over land, IEEE Trans. Geosci. Remote Sens., 42, 11

Levy, R. C., L. A. Remer, J. V. Martins, Y. J. Kaufman, A. Plana-Fattori, J. Redemann, and B. Wenny (2005), Evaluation of MODIS aerosol retrievals over ocean and land during CLAMS, J. Atmos. Sci., 62, 974-992.

Levy, R. C., L. A. Remer, and O. Dubovik (2007a), Global aerosol optical properties and application to Moderate Resolution Imaging Spectroradiometer aerosol retrieval over land, J. Geophys. Res., 112, D13210, doi:10.1029/2006JD007815. 
Levy, R. C., L. A. Remer, S. Mattoo, E. Vermote, and F. Y. J. Kaufman (2007b), Second-generation operational algorithm: Retrieval of aerosol properties over land from inversion of Moderate Resolution Imaging Spectroradiometer spectral reflectance, J. Geophys. Res., 112, D13211, doi:10.1029/2006JD007811.

Martins, J. V., D. Tanre, L. A. Remer, Y. J. Kaufman, S. Mattoo, and R. Levy (2002), MODIS cloud screening for remote sensing of aerosol over oceans using spatial variability, Geophys. Res. Lett., 29(12), 8009, doi:10.1029/2001GL013252.

Matsui, T., S. M. Kreidenweis, R. A. Pielke Sr., B. Schichtel, H. Yu, M. Chin, D. A. Chu, and D. Niyogi (2004), Regional comparison and assimilation of GOCART and MODIS aerosol optical depth across the eastern U.S., Geophys. Res. Lett., 31, L21101, doi:10.1029/ 2004GL021017.

Park, R. J., D. Jacob, J. Chin, and M. R. V. Martin (2003), Sources of carbonaceous aerosols over the United States and implications for natural visibility, J. Geophys. Res., 108(D12), 4355, doi:10.1029/ 2002JD003190.

Park, R. J., D. J. Jacob, B. D. Field, R. M. Yantosca, and M. Chin (2004), Natural and transboundary pollution influences on sulfate-nitrate-ammonium aerosols in the United States: Implications for policy, J. Geophys. Res., 109, D15204, doi:10.1029/2003JD004473.

Park, R. J., D. J. Jacob, N. Kumar, and R. M. Yantosca (2006), Regional visibility statistics in the United States: Natural and transboundary pollution influences, and implications for the Regional Haze Rule, Atmos. Environ., 40, 5405-5423.

Remer, L. A., et al. (2002), Validation of MODIS aerosol retrieval over ocean, Geophys. Res. Lett., 29(12), 8008, doi:10.1029/2001GL013204.

Remer, L. A., et al. (2005), The MODIS aerosol algorithm, products and validation, J. Atmos. Sci., 62, 947-973.

Remer, L. A., D. Tanre, Y. J. Kaufman, R. Levy and S. Mattoo (2006), Algorithm for remote sensing of Tropospheric aerosol from MODIS Collection 005, Product ID MOD04/MYD04 Ref. No. ATBD-MOD96. (Available at http://modis-atmos.gsfc.nasa.gov/_docs/MOD04:MYD04 ATBD C005 revl.pdf)

Singh, H. B., W. H. Bruñe, J. H. Crawford, D. J. Jacob, and P. B. Russell (2006), Overview of the summer 2004 Intercontinental Chemical Trans- port Experiment-North America (INTEX-A), J. Geophys. Res., 111, D24S01, doi:10.1029/2006JD007905.

Smirnov, A., B. N. Holben, T. F. Eck, O. Dubovik, and I. Slutsker (2000), Cloud screening and quality control algorithms for the AERONET database, Remote Sens. Environ., 73, 337-349.

Spurr, R. J. D. (2002), Simultaneous radiative transfer derivation of intensities and weighting functions in a general pseudo-spherical treatment, J. Quant. Spectrosc. Radiat. Transfer, 75, 129-175.

Spurr, R. J. D., T. P. Kurosu, and K. V. Chance (2001), A linearized discrete ordinate radiative transfer model for atmospheric remote sensing retrieval, J. Quant. Spectrosc. Radiat. Transfer, 68, 689-735.

Turquety, S., et al. (2007), Inventory of boreal fire emissions for North America in 2004: The importance of peat burning and pyro-convective injection, J. Geophys. Res., 112, D12S03, doi:10.1029/2006JD007281.

Vermote, E. F., D. Tanre, J. L. Deuze, M. Herman, and J. J. Morcrette (1997), Second simulation of the satellite signal in the solar spectrum, 6S: An overview, IEEE Trans. Geosci. Remote Sens., 35, 675-686.

Wang, J., and S. T. Martin (2007), Satellite characterization of urban aerosols: Importance of including hygroscopicity and mixing state in the retrieval algorithms, J. Geophys. Res., 112, D17203, doi:10.1029/ 2006JD008708.

Weaver, C. J., A. da Silva, M. Chin, P. Ginoux, O. Dubovik, D. E. Flittner, A. Zia, L. A. Remer, B. N. Holben, and W. Gregg (2007), Assimilation of MODIS radiances in a global aerosol transport model, J. Atmos. Sci., 64, doi:10.1175/JAS3838.1

K. Chance, Atomic and Molecular Physics Division, Harvard-Smithsonian Center for Astrophysics, 60 Garden Street, Cambridge, MA 02138, USA.

E. Drury and D. J. Jacob, School of Engineering and Applied Sciences, Harvard University, 29 Oxford Street, Cambridge, MA 02138, USA. (drury@fas.harvard.edu)

R. J. D. Spurr, RT Solutions, Inc., 9 Channing Street, Cambridge, MA 02138, USA.

J. Wang, Department of Geosciences, University of Nebraska, 303 Bessey Hall, Lincoln, NE 68588, USA. 